\title{
Curing reaction and mechanism of phenol- formaldehyde novolac resins for foundry
}

\author{
${ }^{*}$ Yan Shi ${ }^{1}$, Li-feng Wang ${ }^{2}$, Yue Han ${ }^{2}$, Cong-yan Liao ${ }^{1}$, Lin-zhi Xie ${ }^{1}$, and Chun-rong Yang ${ }^{1}$ \\ 1. School of Chemistry and Chemical Engineering, Southwest University, Chongqing 400715, China; \\ 2. Chongqing Changjiang Molding Material Group Co., Inc./ Enterprise Technology Engineering Research Center of Chongqing Powder \\ Functional Materials, Chongqing 400709, China
}

\begin{abstract}
In this study on the curing dynamics of phenol-formaldehyde novolac resins (PFNR) and hexamethylene tetramine (HMTA), two typical commercial PFNR were selected as examples and the curing reactions of the resins with HMTA were studied by differential scanning calorimetry (DSC). Based on the data calculated by the Kissinger equation and the Crane equation, a thermocuring dynamic model was established, from which the process conditions, activation energy, reaction kinetics equation and a first-order reaction of the curing reactions were derived.
\end{abstract}

Key words: phenol-formaldehyde novolac resins used for foundry; hexamethylene tetramine; differential scanning calorimetry; curing reaction and mechanism
CLC numbers: TG221 .2
Document code: $\mathrm{A}$
Article ID: 1672-6421(2016)03-205-06

$P^{\prime}$ henol-formaldehyde novolac resin (PFNR) is an mportant kind of thermoplastic polymer material. Because of the excellent performance of acid resistance, mechanical properties, heat resistance and adhesion, it is widely used in the fields of casting adhesive, anti-corrosion engineering, flame retardant materials, grinding wheel manufacturing etc. ${ }^{[1]}$. The curing reaction of thermosetting resin takes place when it was heated to a certain temperature. While, only when suitable amounts of curing agent is added, the curing reaction of PFNR can effectively go on ${ }^{[2]}$. Hexamethylene tetramine (HMTA) always acts as a curing agent, with which PFNR mixes to induce polymerization and curing reaction. After a series of chemical reactions, such as condensation, closed-loop, addition or catalysis, an irreversible curing reaction of PFNR takes place.

A proper mechanism and influencing factors of the curing reaction, such as curing temperature, reaction time and enthalpy change, are important in actual production. Firstly, a correct reaction mechanism can

\section{*Yan Shi}

Female, Ph. D., senior experimentalist. Her research focus is mainly on materials science and molecular spectroscopy. She has published more than 15 papers and has been awarded 3 invention patents of China.

E-mail: shiyan@swu.edu.cn

Received: 2015-09-07; guide us to choose what kind of resin and curing agent, to control the proper reactant ratio and to adjust the reaction time of different processes of reactions without affecting product performance. So, a correct reaction mechanism can help us to successfully achieve improved production efficiency, improved product quality and the biggest benefit to a company. Secondly, a specific reaction mechanism and influencing factors can contribute to reduce harmful substances by improving reaction conditions or adding an auxiliary agent. Unfortunately, the curing mechanism of PFNR using HMTA as a curing agent is still unclear and there are several different uncertain assumptions ${ }^{[3]}$. Therefore, studies on the reaction mechanism and influencing factors are very important and necessary.

In this study, two PFNRs were selected as examples. After pretreating, the two resins were reacted with HMTA. The curing reactions were studied by differential scanning calorimetry (DSC). Based on the data calculated by the Kissinger equation and the Crane equation, a thermocuring dynamic model was constructed, from which the process conditions, activation energy, reaction kinetics equation and the first-order reaction of the curing reactions were derived. 


\section{Experimental method}

\subsection{Materials and instruments}

Resin A and Resin B (commercial industrial products) were provided by Chongqing Changjiang Molding Materials Group Co., Inc. The speed of polymerization for resin $\mathrm{A}$ is 58 to $65 \mathrm{~s}$ and 85 to $92 \mathrm{~s}$ for resin B. The softening points are 90 to $93{ }^{\circ} \mathrm{C}$ for resin $\mathrm{A}$ and 85 to $90{ }^{\circ} \mathrm{C}$ for resin B. Hexamethylene tetramine (HMTA, pure analysis) was provide by Tianjin Ruijinte Chemicals Co. Ltd. DSC curves were obained using a differential scanning calorimeter (DSC 200 F3, NETZSCH, Germany) with a metal aluminum crucible in an atmosphere of $99.999 \%$ high purity nitrogen.

\subsection{Experimental procedure}

Pretreatment methods: Resin A and resin B were ground into powder and mixed with HMTA in a weight proportion of 100:14. After being mixed fully, it was kept in a $90{ }^{\circ} \mathrm{C}$ temperature bath for $5 \mathrm{~min}$ and ground into a powder after being cooled.

DSC determination method: A suitable amount of mixed resin (about 4.4 to $5.0 \mathrm{mg}$ ) was weighed accurately and then heated by a linear heating mode from $90^{\circ} \mathrm{C}$ to $190^{\circ} \mathrm{C}$ in an atmosphere of high purity nitrogen $(99.999 \%$ ) with a purge gas flow rate of $20 \mathrm{ml} \cdot \mathrm{min}^{-1}$ and a protective gas flow rate of $60 \mathrm{ml} \cdot \mathrm{min}^{-1}$. At different heating rates $\left(5^{\circ} \mathrm{C} \cdot \mathrm{min}^{-1}, 10^{\circ} \mathrm{C} \cdot \mathrm{min}^{-1}, 15^{\circ} \mathrm{C} \cdot \mathrm{min}^{-1}\right.$, $\left.20^{\circ} \mathrm{C} \cdot \mathrm{min}^{-1}, 25^{\circ} \mathrm{C} \cdot \mathrm{min}^{-1}, 30^{\circ} \mathrm{C} \cdot \mathrm{min}^{-1}\right)$, DSC curves were recorded by using corresponding resin (without HMTA, about 3.8 to $4.0 \mathrm{mg}$ ) as a reference.

\section{Results and discussion}

\subsection{Effect of heating rate on curing temperature}

The curing reaction is directly related to the curing temperature, equilibrium temperature and diffusion rate of material. So in this experiment, when the sample weight and sample size are the same as each other, the heat of the curing reaction is basically the same. If mixed resins were heated at different heating rates, initial temperature, peak temperature and terminal temperature of curing reaction would change regularly. Figures 1 and 2 show the effects of different heating rates on DSC curves of resin $\mathrm{A}$ and resin $\mathrm{B}$. The initial temperatures, the peak temperatures and the terminal temperatures of resin $\mathrm{A}$ and resin $B$ were recorded under different heating rates (shown in Table 1). From Table 1, it was found that the curing temperatures $\left(T_{\mathrm{i}}, T_{\mathrm{p}}\right.$ and $T_{\mathrm{t}}$ ) increased as the heating rates were increased. With the curing temperatures plotted against the heating rates, the curing temperature was proportional to the heating rates of mixed resins in a temperature range of 5 to $30^{\circ} \mathrm{C} \cdot \mathrm{min}^{-1}$ and the linear regression equations could be obtained (Fig. 3 and Fig. 4). The correlation coefficients of six linear regression equations are more than $0.96 R$. From the linear equations, the ideal curing temperatures of resin A and resin B can be predicted or deduced.

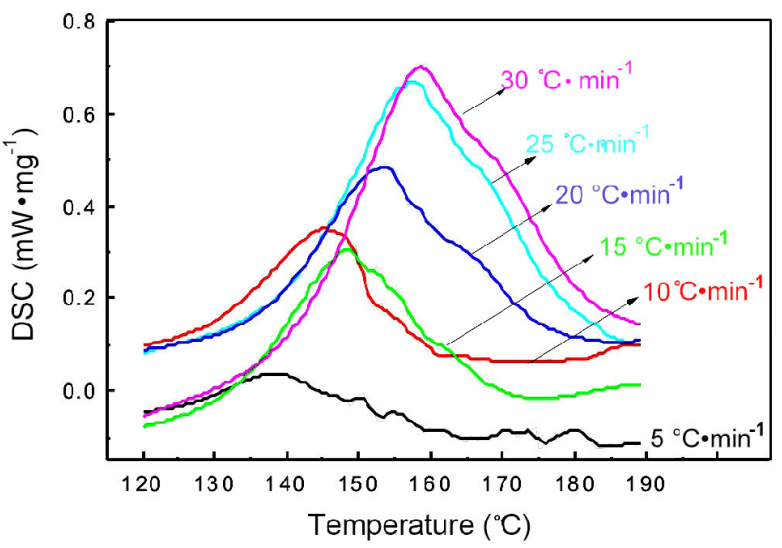

Fig. 1: Effect of different heating rates on DSC curves of resin A

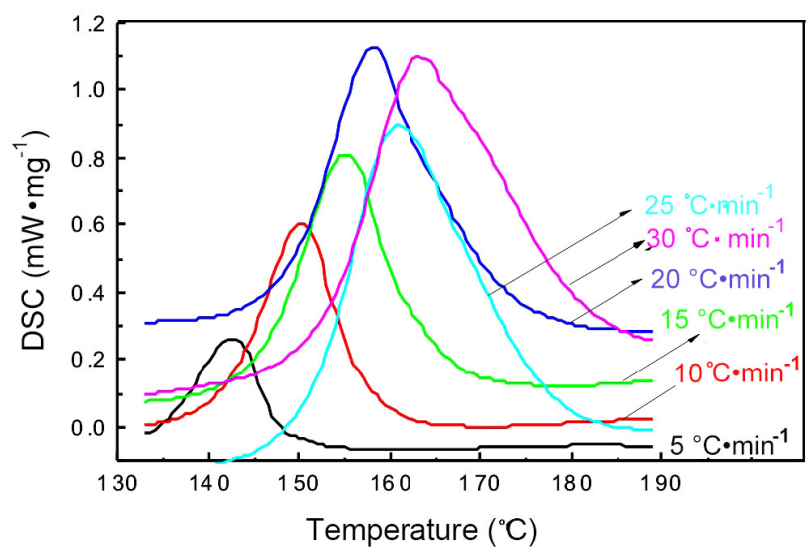

Fig. 2: Effect of different heating rates on DSC curves of resin B

Table 1: DSC parameters of resin A and resin B at different heating rates

\begin{tabular}{|c|c|c|c|c|c|c|}
\hline \multirow{2}{*}{$\begin{array}{c}\text { Heating } \\
\text { rate } \\
\boldsymbol{\beta} \\
{ }^{\circ} \mathrm{C} \cdot \mathrm{min}^{-1}\end{array}$} & \multicolumn{2}{|c|}{$\begin{array}{c}\text { Initial } \\
\text { temperature } \\
T_{\mathrm{i}}\left({ }^{\circ} \mathrm{C}\right)\end{array}$} & \multicolumn{2}{|c|}{$\begin{array}{c}\text { Peak } \\
\text { temperature } \\
T_{\mathrm{p}}\left({ }^{\circ} \mathrm{C}\right)\end{array}$} & \multicolumn{2}{|c|}{$\begin{array}{l}\text { Terminal temperature } \\
\qquad T_{\mathrm{t}}\left({ }^{\circ} \mathrm{C}\right)\end{array}$} \\
\hline & $\begin{array}{c}\text { Resin } \\
\text { A }\end{array}$ & $\begin{array}{c}\text { Resin } \\
\text { B }\end{array}$ & $\begin{array}{c}\text { Resin } \\
\text { A }\end{array}$ & $\begin{array}{c}\text { Resin } \\
\text { B }\end{array}$ & $\begin{array}{c}\text { Resin } \\
\text { A }\end{array}$ & $\begin{array}{c}\text { Resin } \\
\text { B }\end{array}$ \\
\hline 5 & 126.9 & 134.3 & 137.8 & 142.5 & 144.5 & 146.9 \\
\hline 10 & 129.5 & 141.8 & 145.9 & 150.3 & 152.5 & 156.8 \\
\hline 15 & 133.3 & 145.8 & 149.3 & 154.8 & 156.6 & 162.7 \\
\hline 20 & 137.3 & 148.9 & 153.2 & 158.4 & 159.7 & 166.9 \\
\hline 25 & 140.5 & 151.0 & 157.6 & 161.1 & 173.3 & 176.7 \\
\hline 30 & 142.2 & 152.9 & 159.0 & 163.0 & 174.2 & 175.6 \\
\hline
\end{tabular}

\subsection{Curing process for resin $A$ and resin $B$}

In Fig. 3 and Fig. 4 , the curing temperatures $\left(T_{\mathrm{i}}, T_{\mathrm{p}}\right.$ and $\left.T_{\mathrm{t}}\right)$ curves were extrapolated to the horizontal zero. In accordance with the principle of the least squares, when the heating rate is zero, the curing temperature $\left(T_{\mathrm{i}}, T_{\mathrm{p}}\right.$ and $\left.T_{\mathrm{t}}\right)$ corresponds to the ideal curing temperatures: approximate gelling temperature $\left(T_{\text {ag }}\right)$, ideal curing temperature $\left(T_{\text {ic }}\right)$ and post processing temperature $\left(T_{\mathrm{pp}}\right)$, respectively. The values of $T_{\mathrm{ag}}, T_{\mathrm{ic}}$ and $T_{\mathrm{pp}}$ of resin A and resin B are shown in Table 2. 


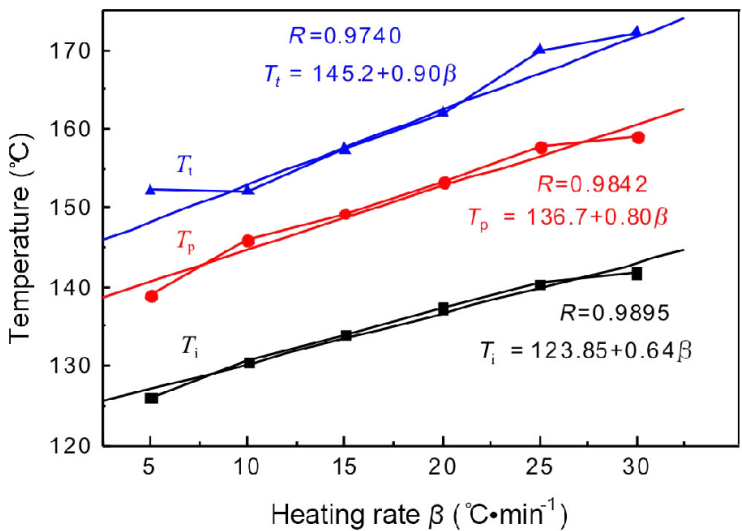

Fig. 3: Linear regression equations of temperature $\left(T_{i}, T_{\mathrm{p}}\right.$ and $\left.T_{\mathrm{t}}\right)$ versus heating rates of resin A

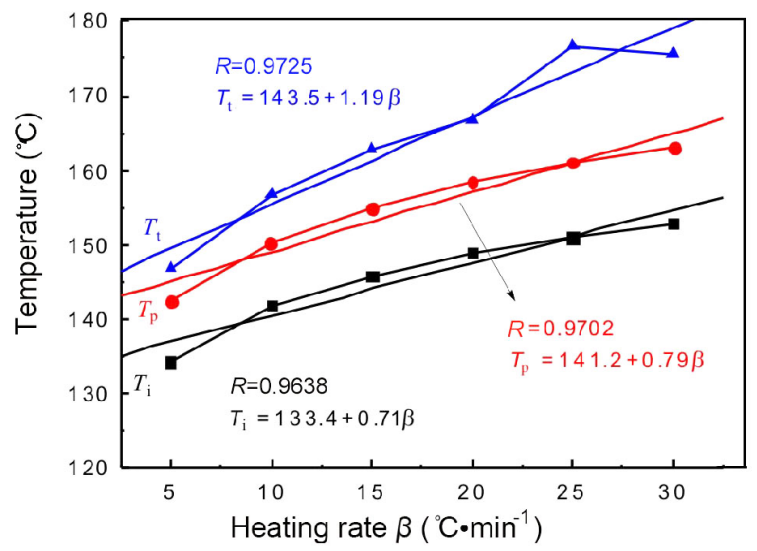

Fig. 4: Linear regression equations of temperature $\left(T_{\mathrm{i}}\right.$, $T_{p}$ and $T_{t}$ ) versus heating rates of resin $\mathrm{B}$

Table 2: Ideal curing temperatures of resin A and resin B

$\begin{array}{lccc}\text { Sample } & \begin{array}{c}\text { Ideal curing temperature }\left({ }^{\circ} \mathrm{C}\right) \\ \text { Approximate } \\ \text { gelling } \\ \text { temperature } \\ \left({ }^{\circ} \mathrm{C}\right)\end{array} & \begin{array}{c}\text { Ideal curing } \\ \text { temperature } T_{\text {ic }} \\ \left({ }^{\circ} \mathrm{C}\right)\end{array} & \begin{array}{c}\text { Post processing } \\ \text { temperature } T_{\text {pp }} \\ \left({ }^{\circ} \mathrm{C}\right)\end{array} \\ \text { Resin A } & 123.85 & 136.70 & 145.15 \\ \text { Resin B } & 133.41 & 141.17 & 143.53\end{array}$

It was found from Table 2 that the two resins show a temperature difference of $10{ }^{\circ} \mathrm{C}$ degrees for $T_{\text {ag }}$, about $5{ }^{\circ} \mathrm{C}$ degrees for $T_{\mathrm{ic}}$ and 1.5 degrees for $T_{\mathrm{pp}}$. Furthermore, for resin A, $T_{\mathrm{pp}}-T_{\mathrm{ag}}=21.3{ }^{\circ} \mathrm{C}$; for resin $\mathrm{B}, T_{\mathrm{pp}}-T_{\mathrm{ag}}=10.1{ }^{\circ} \mathrm{C}$. So, it could be inferred that the curing reaction takes place at lower temperature for resin $\mathrm{A}$ and it would take more time to finish the curing reaction for resin $\mathrm{A}$.

\subsection{Calculation of activation energies}

Activation energies of the curing reaction for resin can be calculated by the Kissinger equation and the Ozawa equation. In this paper, both methods were used for comparison of resin $\mathrm{A}$ and resin $\mathrm{B}$.

\subsubsection{Calculation of apparent activation energy by the} Kissinger equation

Kissinger's corrected kinetic equation is the most typical and extensive model that is prevailingly applied to evaluate the kinetics. When reaction order keeps a constant ( $n$-th order reaction) and the maximum speed of a reaction occurs at the peak temperature, the Kissinger equation can be used to calculate activation energy of a curing reaction. So, a line can be drawn through the experimental data from thermal analysis and the Kissinger's corrected kinetic equation. Eq. (1) expresses the Kissinger's corrected kinetic equation:

$$
\ln \left(\frac{\beta}{T_{P}^{2}}\right)=\ln \left(\frac{A R}{E}\right)-\frac{E}{R} \times \frac{1}{T_{p}}
$$

where, $\beta$ represents the heating rate $\left(\mathrm{K} \cdot \mathrm{min}^{-1}\right) . T_{p}$ is the peak temperature $(\mathrm{K}) . A$ is the pre-exponential factor $\left(\mathrm{min}^{-1}\right)$ which is related to the collision frequency and the fraction of molecules that collide with the correct orientation. $R$ is the ideal gas constant in energy units $\left(8.1344 \mathrm{~J} \cdot \mathrm{mol}^{-1} \cdot \mathrm{K}^{-1}\right) . E$ is the activation energy $\left(\mathrm{kJ} \cdot \mathrm{mol}^{-1}\right)$. Therefore, using the slope of the line and Eq. (1), the $E$ of the sample can be determined ${ }^{[4-7]}$.

$$
\ln \left(\frac{\beta}{T_{P}^{2}}\right) \text { and } \frac{1}{T_{p}} \text { items could be obtained by DSC results }
$$

of the heating rate and exothermic $T_{\mathrm{p}}$. Therefore, $\frac{1}{T_{p}}$ was represented for $x$ axis and $\ln \left(\frac{\beta}{T_{P}^{2}}\right)$ denoted for $y$ axis to draw

a figure. After six heating rates and six $T_{\mathrm{p}}$ were substituted into Eq. (1), a graph and a linear regression equation could be acquired:

$$
y=a+b x
$$

By taking $x$ axis and $y$ axis as $\frac{1}{T_{p}}$ and $\ln \left(\frac{\beta}{T_{P}^{2}}\right)$, so,

$$
b=\text { slope }=-\frac{E}{R}
$$

Through transposing Eq. (3), a value of $E$ could be obtained:

$$
E=b \times 8.314 \times 10^{-3} \mathrm{~kJ} \cdot \mathrm{mol}^{-1}
$$

As mentioned above, by the Kissinger's corrected kinetic equation, the $E$ of resin $\mathrm{A}$ and resin B can be acquired ${ }^{[8]}$ (shown in Table 3 and Fig. 5).

\subsubsection{Calculation of apparent activation energy by using Ozawa equation}

The Ozawa equation is also frequently used to treat nonisothermal crystallization kinetics. The Ozawa equation was derived from the Avrami equation by assuming that the non-isothermal crystallization process was composed of infinitesimally small isothermal crystallization steps.

The value of activation energy can be directly calculated from the Ozawa equation which avoids the reaction mechanism 
Table 3: Kinetic parameters of curing reaction in the Kissinger equation

\begin{tabular}{|c|c|c|c|c|c|c|}
\hline \multirow[b]{2}{*}{$\begin{array}{c}\boldsymbol{\beta} \\
\left(\mathrm{K} \cdot \mathrm{min}^{-1}\right)\end{array}$} & \multicolumn{2}{|c|}{$T_{p}(\mathrm{~K})$} & \multicolumn{2}{|c|}{$\ln \left(\beta / T_{p}^{2}\right)$} & \multicolumn{2}{|c|}{$1000 / T_{p}$} \\
\hline & $\underset{\text { A }}{\text { Resin }}$ & $\begin{array}{c}\text { Resin } \\
\text { B }\end{array}$ & $\begin{array}{c}\text { Resin } \\
\text { A }\end{array}$ & $\begin{array}{c}\text { Resin } \\
\text { B }\end{array}$ & $\begin{array}{c}\text { Resin } \\
\text { A }\end{array}$ & $\begin{array}{c}\text { Resin } \\
\text { B }\end{array}$ \\
\hline 5 & 412.05 & 415.65 & -10.43 & -10.45 & 2.43 & 2.41 \\
\hline 10 & 419.05 & 423.45 & -9.77 & -9.79 & 2.39 & 2.36 \\
\hline 15 & 422.45 & 427.95 & -9.38 & -9.41 & 2.37 & 2.34 \\
\hline 20 & 426.35 & 431.55 & -9.11 & -9.14 & 2.35 & 2.32 \\
\hline 25 & 430.75 & 434.25 & -8.91 & -8.93 & 2.32 & 2.30 \\
\hline 30 & 432.15 & 436.15 & -8.74 & -8.75 & 2.31 & 2.29 \\
\hline
\end{tabular}

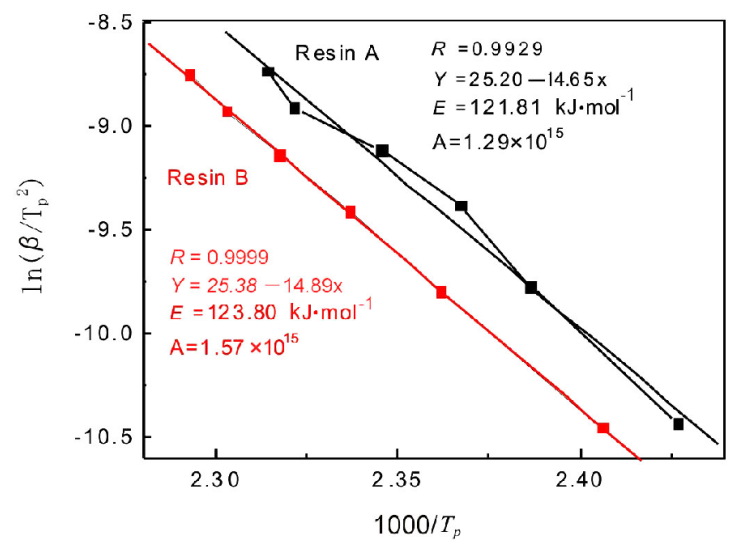

Fig. 5: Typical Kissinger plot from experimental data at six heating rates for resin $A$ and resin $B$

function. So, the errors caused by different reaction mechanism functions can also be avoided. The expression of the Ozawa equation is:

$$
E=-\frac{R}{1.052} \times \frac{\mathrm{d}(\ln \beta)}{\mathrm{d}\left(1 / \mathrm{T}_{\mathrm{p}}\right)}
$$

where, $\beta$ represents the heating rate $\left(\mathrm{K} \cdot \mathrm{min}^{-1}\right) . T_{\mathrm{p}}$ is the peak temperature $(\mathrm{K}) . R$ is the ideal gas constant in energy units $\left(8.1344 \mathrm{~J} \cdot \mathrm{mol}^{-1} \cdot \mathrm{K}^{-1}\right) . E$ is the activation energy $\left(\mathrm{kJ} \bullet \mathrm{mol}^{-1}\right)$. Therefore, using the slope of the line and Eq. 5, $E$ can be calculated.

From Eq. 5, when item $\ln \beta$ plotted to $1 / T_{\mathrm{p}}$, the slope could be used to calculate the curing reaction activation energy $(E)$. Relevant data is shown in Table 4 and Fig. 6.

From Table 4, it can be found that the values of activation energies for resin A or resin B calculated by the Kissinger equation and the Ozawa equation respectively show little

Table 4: Activation energy calculated by the Kissinger equation and the Ozawa equation

\begin{tabular}{|c|c|c|c|}
\hline \multirow[b]{2}{*}{ Sample } & \multicolumn{3}{|c|}{ Activation energy $E\left(\mathrm{~kJ} \cdot \mathrm{mol}^{-1}\right)$} \\
\hline & $\begin{array}{l}\text { Kissinger } \\
\text { equation }\end{array}$ & $\begin{array}{l}\text { Ozawa } \\
\text { equation }\end{array}$ & Average \\
\hline Resin A & 121.81 & 115.23 & 118.52 \\
\hline Resin B & 123.80 & 118.47 & 121.14 \\
\hline
\end{tabular}

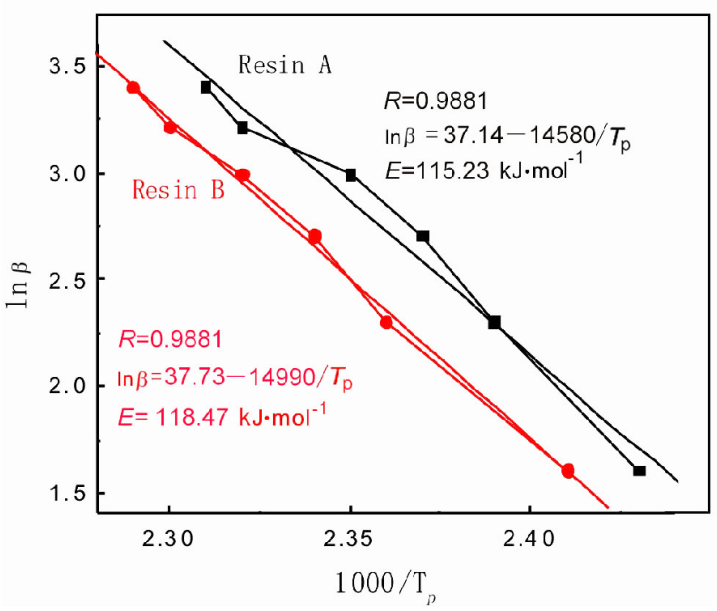

Fig. 6: Ozawa plot from the experimental data at six heating rates for resin $A$ and resin $B$

difference and the activation energy value for resin A is 118.52 $\mathrm{kJ} \bullet \mathrm{mol}^{-1}$ and $121.14 \mathrm{~kJ} \bullet \mathrm{mol}^{-1}$ for resin $\mathrm{B}$ on average.

Comparing the activation energy values of the two resins, although the heating rates show effects on the curing temperature, the values of activation energy are very close to each other and the process of curing reaction for both of the resins are the same also.

\subsubsection{Calculation of curing reaction order}

As $E$ values were acquired, the Crane equation can be deduced from the Kissinger equation and was used to calculate the curing reaction series ${ }^{[9-10]}$. The Crane equation shows as Eq. 6:

$$
\frac{\mathrm{d}(\ln \beta)}{\mathrm{d}\left(1 / \mathrm{T}_{\mathrm{p}}\right)}=-\left(\frac{E}{n R}+2 T_{P}\right)
$$

where, $E$ is the apparent activation energy with $\mathrm{J} \bullet \mathrm{mol}^{-1} . n$ is reaction order and the value of $n$ can be obtained from the plot of $\ln \beta$ versus $1 / T_{\mathrm{p}}$.

Figure 7 shows the plot of $\ln \beta$ versus $1 / T_{\mathrm{p}}$ for the exothermic peak of the two resins. The figure also shows a good linear

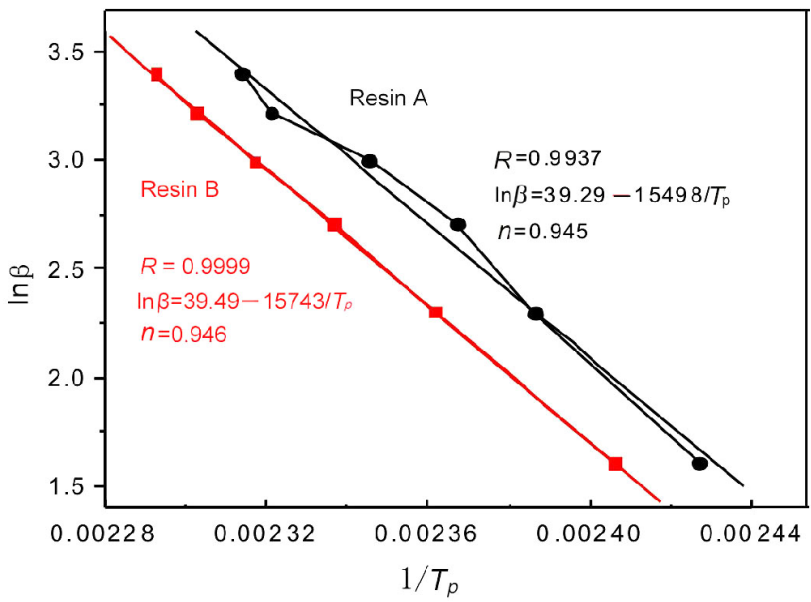

Fig. 7: Relationship between $\ln \beta$ and $1 / T_{\mathrm{p}}$ 
correlation. The reaction order $(n)$ was obtained from the slope of the curves (equal -15498 and -15743 for resin A and resin B respectively) and was calculated as 0.945 and 0.946 for resin A and resin $\mathrm{B}$.

\subsection{Calculation of curing reaction kinetics equation}

From the above data and spectral analysis, correlation coefficients are all above 0.99 , indicating that using the above equation for this system is reasonable. The reaction order $(n)$ were calculated as 0.945 and 0.946 for resin A and resin B, respectively, which met the condition of $0.9 \leqslant n \leqslant 1$, so the firstorder kinetics reaction equation can be used as Eq. 7:

$$
\frac{\mathrm{d} \alpha}{\mathrm{dt}}=k(1-\alpha)
$$

where, $\alpha$ is the curing degree.

Another Arrhennius shows as Eq. 8:

$$
K=A \exp \left(\frac{-E}{R T}\right)
$$

Combining Eq. 7 and Eq. 8, the first-order kinetic equation can be obtained as Eq. 9:

$$
\frac{\mathrm{d} \alpha}{\mathrm{dt}}=A \exp \left(\frac{-E}{R T}\right)(1-\alpha)
$$

Taking the curing kinetics parameters into the above equation, the curing reaction kinetic equation of the two resins can be expressed as Eq. 10 and Eq. 11:

Resin A:

$$
\frac{\mathrm{d} \alpha}{\mathrm{dt}}=1.29 \times 10^{15} \exp \left(1.18 \times 10^{5} / R T\right)(1-\alpha)
$$

Resin B:

$$
\frac{\mathrm{d} \alpha}{\mathrm{dt}}=1.57 \times 10^{15} \exp \left(1.21 \times 10^{5} / R T\right)(1-\alpha)
$$

From the curing reaction kinetic equations, the curing time for the resin to achieve the desired curing degree at a certain temperature or the required temperature for the resin to achieve the desired curing degree at a certain period of time can be predicted. Further predictions can also be achieved by providing reaction characteristics at a constant temperature and theoretical references for optimization of process parameters of the two resins.

\subsection{Discussion}

In the previous studies, the curing mechanism of the reaction of PFNR and HMTA was still unclear and there were several following hypotheses:

The first one was that the heated HMTA decomposes into diamine, and diamine leads to a dehydration reaction with hydroxyl groups of Novolac resin. A reticulate structure forms and the curing reaction takes place. The second view was that free formaldehyde, the hydrolysis product of HMTA, leads to an additional reaction with Novolac resin, which makes the resin a linear molecule to a body structure. The third one was that the heated HMTA decomposes into formaldehyde which reacts with the $o, p$-active site of Novolac resin to a methine key bridge by dehydration. The resin forms a body structure from a linear one and an insoluble, infusible cured product formed by further poly-condensation of the body structure ${ }^{[11-12]}$.

Whatever the kind of the curing mechanisms, a curing agent is necessary for the curing process of PFNR. In terms of HMTA, when the amount of added resin keeps constants, resincoated sand core mold can not be completely removed from the hot box mold owing to the lower strength, if the amount of HMTA is very low. The strength of resin-coated sand core/mold increases with an increase in the amount of HMTA. Further increasing the amount of HMTA, the strength of the sand core/ mold does not increase anymore. That is to say, the quality of the resin-coated sand core/mold used for foundry is directly related to the amount of added HMTA. A first-order reaction shows a relevant with only one reactant's concentration, so the conclusion that the curing reaction of PFNR and HMTA was a first-order reaction conforming to the result of engineering application.

Of course, the proofs to prove a first-order curing reaction made by this research are not enough and more detailed explanation of the mechanism needs further exploration.

\section{Conclusions}

(1) The curing onset temperature, peak temperature and ending temperature of PFNR were determined by different heating rates of DSC determination and the result can be used for presuming curing process and providing some applications for actual production.

(2) The physical parameters obtained by accurate and reproductive DSC method can be used for calculating the activation energy and reaction order, which help us to understand the reaction step and to speculate on the reaction model.

(3) Other PFNR can also be investigated by the DSC method introduced by this paper, so the application prospect is very broad.

(4) These experimental results can guide us to solve the problem of sand core's thermal behavior existing in moulding materials and provide theoretic evidence for the curing process in manufacture.

(5) These experimental results have important actual implications for a moulding materials enterprise to control the quality of PFNR and optimize the process and compositions for producing resins.

\section{References}

[1] Yang Guodong, Hao Lichang, Yang Jian, et al. Progress in research of Novolac resin for foundry. Foundry, 2010, 59: 1083-1087. (In Chinese)

[2] Li Hongjuan. Study on the time-of-flight mass spectrometry of phenolic resin under different synthesis conditions. Master's 
degree thesis, East China Normal University, 2010. (In Chinese)

[3] Chen Shaonan, Yang Guodong, Yang Zhanfeng, et al. Review on Novolak resin coated sand. Hot Working Technology, 2008, 37: 117-119. (In Chinese)

[4] Kissinger H E. Reaction kinetics in differential thermal analysis. Analytical Chemistry, 1957, 29: 1702-1706.

[5] Soliman A. Derivation of the Kissinger equation for nonisothermal glass transition peaks. Journal of Thermal Analysis and Calorimetry, 2007, 89: 389-392.

[6] Chou W J, Wang C C, Chen C Y, et al. Thermal behaviors of polyimide with plasma-modified carbon nanotubes. Polymer Degradation and Stability, 2008, 93: 745-752.

[7] You M L, Liu M Y, Wu S H, et al. Thermal explosion and runaway reaction simulation of lauroyl peroxide by DSC tests. Journal of Thermal Analysis and Calorimetry, 2009, 96: 777782.
[8] Chen Hongjiang, Wu Min, Yu Xinhai, et al. Study on curing kinetics of a novel epoxy resin adhesive. Adhesion, 2009, 30: 43-45. (In Chinese)

[9] Crane L W, Dynes P J, and Kaelble D H. Analysis of curing kinetics in polymer composites. Journal of Polymer Science: Polymer Letters Edition, 1973, 11: 533-540.

[10] Liu L and Ye Z. Effects of modified multi-walled carbon nanotubes on the curing behavior and thermal stability of boron phenolic resin. Polymer Degradation and Stability, 2009, 94: 1972-1978.

[11] Gu Chengzhong, Lin Yongwei, Shi Meiling, et al. Discussion in the relationship of curing agent and property of thermoplastic phenolic resin. Non-Metallic Mines, 1991, 2: 17. (In Chinese)

[12] Zhang Chao. Kinetic study of phenolic formaldehyde resin cure. Master's degree thesis, Wuhan University of Technology, 2010. (In Chinese) 